\title{
Electro-chemical deposition of nano hydroxyapatite-zinc coating on titanium metal substrate
}

\author{
N. A. El-Wassefy ${ }^{1 *}$, F. M. Reicha ${ }^{2}$ and N. S. Aref $^{1}$
}

\begin{abstract}
Background: Titanium is an inert metal that does not induce osteogenesis and has no antibacterial properties; it is proposed that hydroxyapatite coating can enhance its bioactivity, while zinc can contribute to antibacterial properties and improve osseointegration.

Aims: A nano-sized hydroxyapatite-zinc coating was deposited on commercially pure titanium using an electrochemical process, in order to increase its surface roughness and enhance adhesion properties.

Methods: The hydroxyapatite-zinc coating was attained using an electro-chemical deposition in a solution composed of a naturally derived calcium carbonate, di-ammonium hydrogen phosphate, with a pure zinc metal as the anode and titanium as the cathode. The applied voltage was -2.5 for $2 \mathrm{~h}$ at a temperature of $85^{\circ} \mathrm{C}$. The resultant coating was characterized for its surface morphology and chemical composition using a scanning electron microscope (SEM), energy dispersive x-ray spectroscope (EDS), and Fourier transform infrared (FT-IR) spectrometer. The coated specimens were also evaluated for their surface roughness and adhesion quality.

Results: Hydroxyapatite-zinc coating had shown rosette-shaped, homogenous structure with nano-size distribution, as confirmed by SEM analysis. FT-IR and EDS proved that coatings are composed of hydroxyapatite (HA) and zinc. The surface roughness assessment revealed that the coating procedure had significantly increased average roughness $(\mathrm{Ra})$ than the control, while the adhesive tape test demonstrated a high-quality adhesive coat with no laceration on tape removal.

Conclusions: The developed in vitro electro-chemical method can be employed for the deposition of an even thickness of nano HA-Zn adhered coatings on titanium substrate and increases its surface roughness significantly.
\end{abstract}

Keywords: Hydroxyapatite-zinc coating, Titanium metal, Surface roughness, Surface morphology, Coating adhesion, Electrochemical deposition

\section{Background}

Titanium metal is one of the most widely used biomedical orthopedic materials because of its decent mechanical properties [1]. However, as an inert material, it cannot induce osteogenesis and has no antibacterial properties [2]. In order to improve surface bioactivity of titanium substrates, numerous methods have been proposed to cover it with bio-ceramic coatings [1]. Various clinical studies demonstrated that the hydroxyapatite coating

\footnotetext{
* Correspondence: nohahmed@mans.edu.eg

${ }^{1}$ Dental Biomaterials Department, Faculty of Dentistry, Mansoura University,

35516 El Gomhoria St., Mansoura, Egypt

Full list of author information is available at the end of the article
}

of prosthesis can promote earlier osseous response which could increase the prosthesis fixation and the bonding strength [3-5].

Titanium implants are usually placed in contact with bones and gingival tissues so they are partially exposed to the oral cavity during and after implantation. This increases the hazard of bacterial infection, which is known as peri-implantitis [6, 7].

For centuries, Zinc ( $\mathrm{Zn})$ as one of the essential elements of tissues in the human body has a stimulating role in the metabolism of bones and has been used as bacteriostatic and bactericidal agents [8, 9]. Zinc can enhance the retention strength and osseointegration of 
implants [10, 11], by stimulating alkaline-phosphatase activity and collagen production, thus can increase bone deposition and reduce bone resorption [12]. Zn deficiency results in skeletal changes, including retardation of skeletal growth [10] and prolonged bone recovery [13]. Moreover, Zn species are also known to possess excellent antibacterial qualities. Zinc showed inhibitory effects against several bacteria, including Streptococcal mutans [14-16].

The metals' antibacterial activity has been contingent on their contact surface; thus, a greater nanoparticles' surface area permits larger interfaces and increases their interactions with other particles [17].

Although HA coatings revealed an enhanced bone attachment and thus better implants integration, long-term coating stability is quite a provoking concern [18]. Numerous coating techniques like plasma spraying, sol-gel, electrophoretic deposition, electro deposition have been employed to deposit hydroxyapatite on titanium implants. Plasma spraying is the most widely used technique for coating, but it leads to decomposition of $\mathrm{HA}$ due to the high temperature used, and it cannot be employed for complex structures. In electrophoretic deposition, high voltage was applied to the metal surface in order to attract the dispersed particles which leads to anodic polarization of metal substrate. This might increase the corrosion risk of metal and suppress the adhesion of HA particles [19-21]. Electro-chemical deposition (ED) is a frequently used approach with increasing popularity, due to variability of coating composition, process simplicity, and its applicability for multidimensional implant surfaces [22].

The aim of the present work was to develop welladhered and uniform hydroxyapatite-zinc coatings on titanium metal substrate, through an in vitro electrochemical deposition method. The coating was characterized for functional chemical group, surface morphology, surface chemical analysis, surface roughness, and coat adhesive bonding by Fourier transform infrared spectrometer (FT-IR), scanning electron microscope (SEM), energy dispersive spectroscope (EDS), profilometer, and tape adhesive test respectively.

\section{Methods}

\section{Cathode preparation}

Commercially pure $\mathrm{Ti}(\mathrm{CpTi})$ grade II specimens were cut down into plates with dimensions $10 \times 10 \times 2 \mathrm{~mm}$ and used as substrates (cathode material) for depositing $\mathrm{HA}$ and $\mathrm{Zn}$. CpTi specimens were polished with successive grades of silicon carbide papers, ultra-sonicated in acetone (99.5\%, EM Science), rinsed in distilled water, and then air dried at room temperature, before they were used for the electro-chemical process.

\section{Electro-chemical deposition of HA and $\mathrm{Zn}$}

The electro-chemical deposition process was carried in an electrolytic solution. The Ca source of the electrolyte was prepared from dry cuttlebone (CB) (Sepia officinalis L., from the Mediterranean Sea). The CB was cut into blocks and immersed into 5\% household bleach $\mathrm{NaClO}$ for 2 days, in order to eliminate the organic component [23], then rinsed with water and dried in an oven at $80^{\circ}$ $\mathrm{C}$ for $6 \mathrm{~h}$. The starting $\mathrm{CaCO}_{3}$ material of $\mathrm{CB}$ was made to react with nitric acid 69\% (SD Fine Chem Limited, India) to form $\mathrm{Ca}\left(\mathrm{NO}_{3}\right)_{2}$ solution in water. After the complete evolution of $\mathrm{CO}_{2}$, water was evaporated by heating and the resultant powder was examined by FTIR spectrometer (Nicolet iS10, Thermo Electron Corporation, UK) which utilized the selected range of 400 to 4000 wave numbers $\left(\mathrm{cm}^{-1}\right)$ to confirm its chemical structure of $\mathrm{Ca}\left(\mathrm{NO}_{3}\right)_{2} \cdot 4 \mathrm{H}_{2} \mathrm{O}$. The other salts were purchased from Sigma Aldrich and added to form an electrolytic solution containing $0.6 \mathrm{M} \mathrm{Ca}\left(\mathrm{NO}_{3}\right)_{2} \cdot 4 \mathrm{H}_{2} \mathrm{O}$, $0.36 \mathrm{M}\left(\mathrm{NH}_{4}\right) \cdot 2 \mathrm{HPO}_{4}, 1 \mathrm{M} \mathrm{NaNO}_{2}, 6 \% \mathrm{H}_{2} \mathrm{O}_{2}$, and $\mathrm{NH}_{4} \mathrm{OH}$ to adjust the solution $\mathrm{pH}$ to 6 . Pure zinc $(\mathrm{Zn})$ particles (Zinc Tres Pur, Prolabo, N 29050, N=99.999) were pressed in a bench press; Craver Laboratory Press (Model C 31000-823, USA) to produce a $10 \times 10 \times 2 \mathrm{~mm}$ plates that acted as the anode. Platinum wires were used to hang the electrodes in the solution. A thermometer was used to monitor the temperature during the process. The deposition process was carried out with a power supply unit (LT ECOS, 7972, Italy) by applying an electrode potential of $\sim 2.5 \mathrm{~V}$ at $85{ }^{\circ} \mathrm{C}$ temperature stabilized by a thermostatic water bath (MLW, U4, 74010, Germany) for $2 \mathrm{~h}$, during the deposition process a continuous stirring was carried out by a magnetic stirrer. The electrochemical deposition setup is shown in the schematic diagram in Fig. 1. After the deposition, specimens were taken out from the electrolytic bath, rinsed with deionized water, and left to dry for $24 \mathrm{~h}$ on a clean bench. The coated CpTi specimens were then sintered at $400{ }^{\circ} \mathrm{C}$ for $2 \mathrm{~h}$ in an electric furnace with a heating rate of $5{ }^{\circ} \mathrm{C} / \mathrm{min}$ and gradually cooled to room temperature inside the furnace.

\section{Characterization of the deposited HA-Zn coating Infrared analysis}

The coating was scrapped from Ti specimen's surface and investigated for its chemical structure using FTIR spectroscopy. The powder was investigated by double-beam dispersive IR spectrometer (Nicolet iS10, Thermo Electron Corporation, UK) which utilized the selected range of 400 to 4000 wave numbers $\left(\mathrm{cm}^{-1}\right)$ at $4 \mathrm{~cm}^{-1}$ resolution and averaging of 100 scans. Two milligrams of scrapped powder was mixed with $300 \mathrm{mg}$ of $\mathrm{KBr}$ and pressed into a disc before the measurement. 


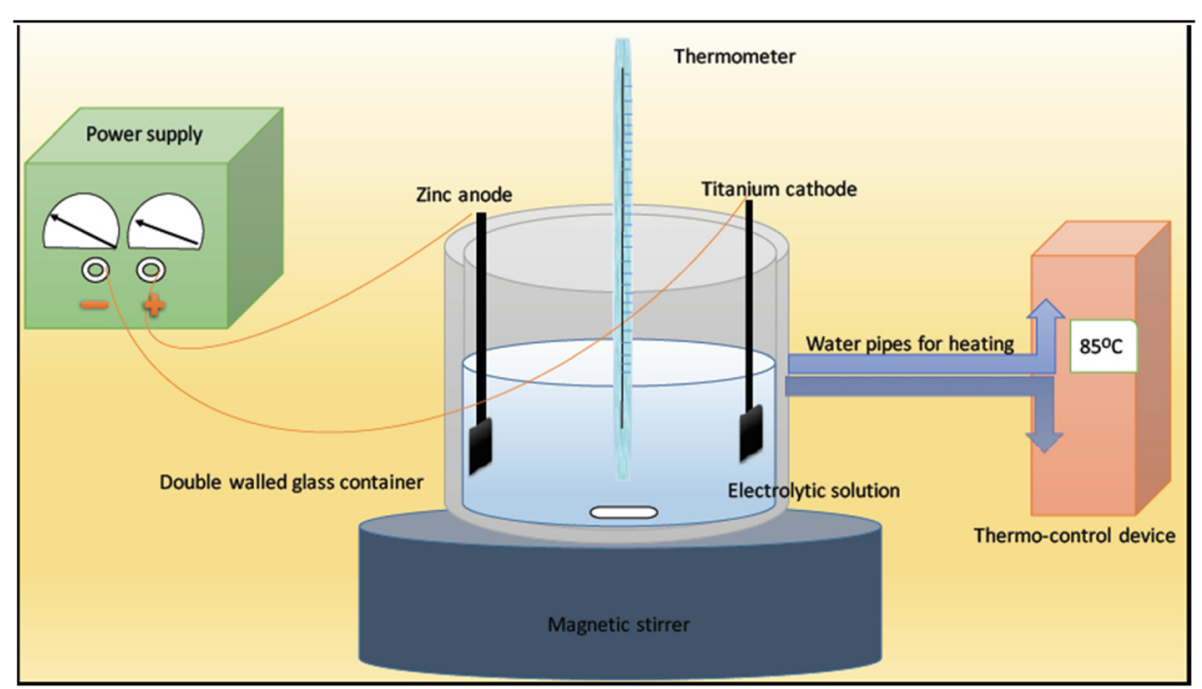

Fig. 1 Graphical presentation of the electrochemical-deposition coating process' equipment

\section{Surface characterization of coatings}

Scanning electron microscope (SEM) (JSM 6300, JEOL, Japan) and energy dispersive spectroscope (EDS) were used to examine the morphological qualities and the elemental composition of the HA- $\mathrm{Zn}$ deposits. The working distance was $15 \mathrm{~mm}$ at $20 \mathrm{~V}$. Three specimens were examined for each group of the study.

\section{Surface-mechanical testing of coatings}

Roughness of coatings Specimens of control and HA-Zn coated groups were evaluated by a surface roughness profilometer tester (Surftest SJ-210, Mitutoyo Corporation, Tokyo, Japan,) according to ISO 4287-1997 [24] with a diamond tip radius of $5 \mu \mathrm{m}$, a scanning speed $0.5 \mathrm{~mm} / \mathrm{s}$, a resolution of $0.01 \mu \mathrm{m}$, a Gaussian filter, and a cut-off length of $8 \mathrm{~mm}$. Seven specimens from each group were scanned and evaluated for the average roughness parameter, each specimen was scanned five times, and the mean was calculated in $\mu \mathrm{m}$. The roughness parameter $(\mathrm{Ra})$ values were compared for statistical significance using the Student $t$ test in SPSS software version 20 (SPSS Inc. Chicago, IL, USA).

Coating adhesion test The adhesion of coating is qualitatively assessed by the tape test. A standard test method (Tape test-ASTM D 3359-97) was used for assessing the adhesion of the HA-Zn coating on the titanium substrate. In this method, a part of a pressure-sensitive adhesive tape (masking tape, M\&G pen AJD97355) is

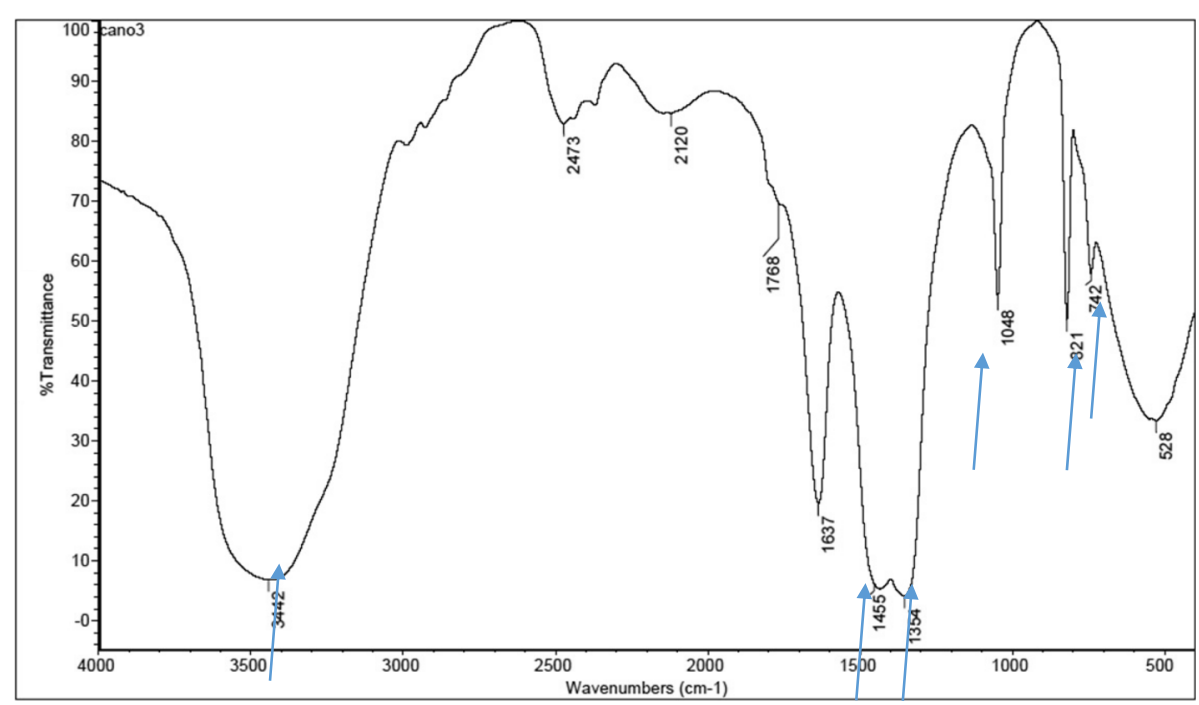

Fig. 2 IR spectra of $\mathrm{Ca}\left(\mathrm{NO}_{3}\right)_{2} \cdot 4 \mathrm{H}_{2} \mathrm{O}$ powder prepared from a natural source (CB) 


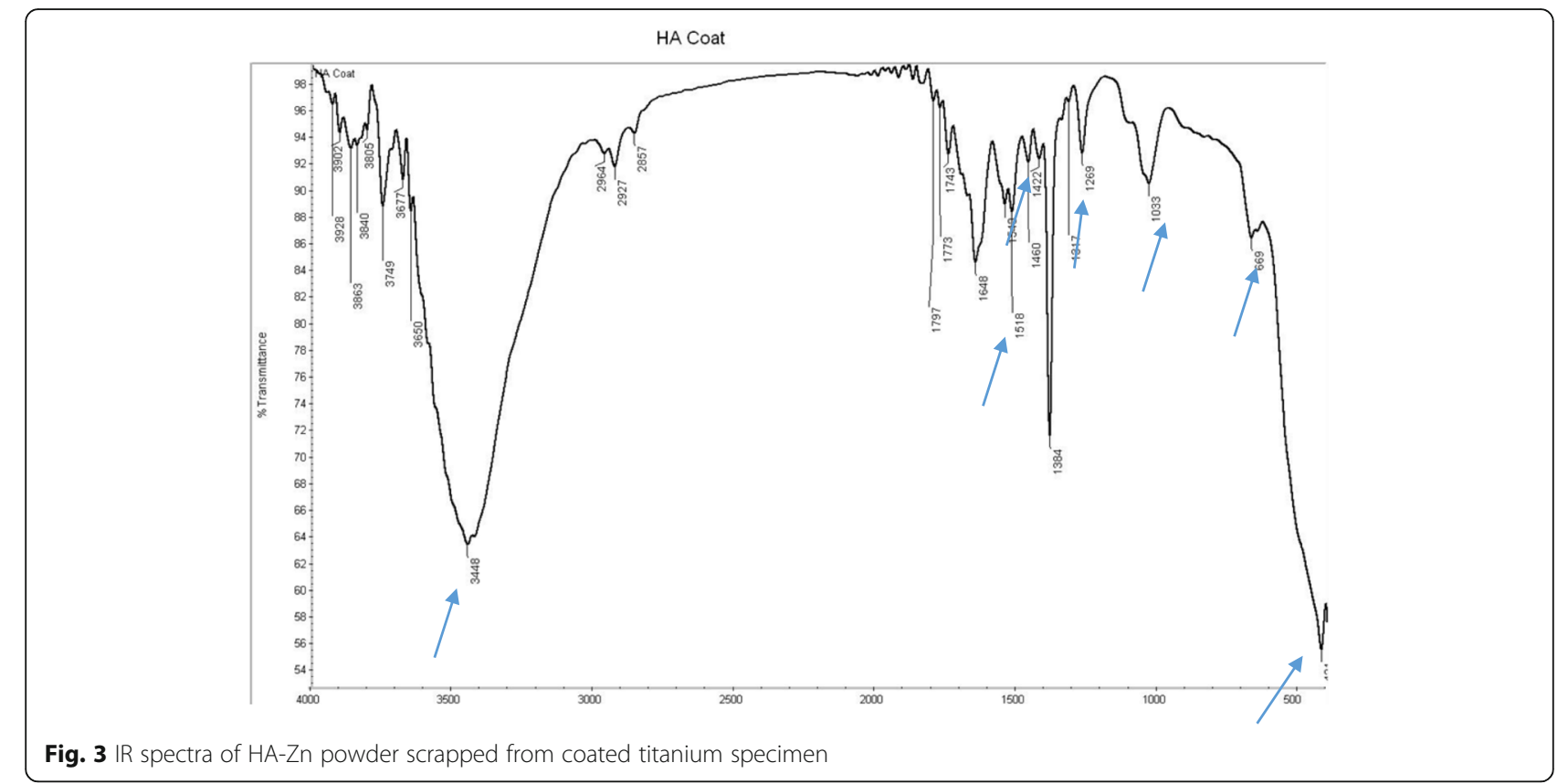

pressed against the coating by the use of a pencil eraser for $90 \mathrm{~s}$. The tape is then rapidly removed (without jerk movements) at $180^{\circ}$ angle, and the degree of film removal is detected when the tape is pulled off. Because an integral coating with substantial adhesion is often not detached at all, the sternness of the test is typically improved by making a figure $\mathrm{X}$ cutting into the coat using a sharp scalpel with enough pressure to reach the metal substrate, then applying the tape and remove it. The denuded area is inspected for removal of coating from the substrate, and then the adhesion is ranked by relating the detached part of the coat versus a recognized rating scale. The test is repeated for three other locations in

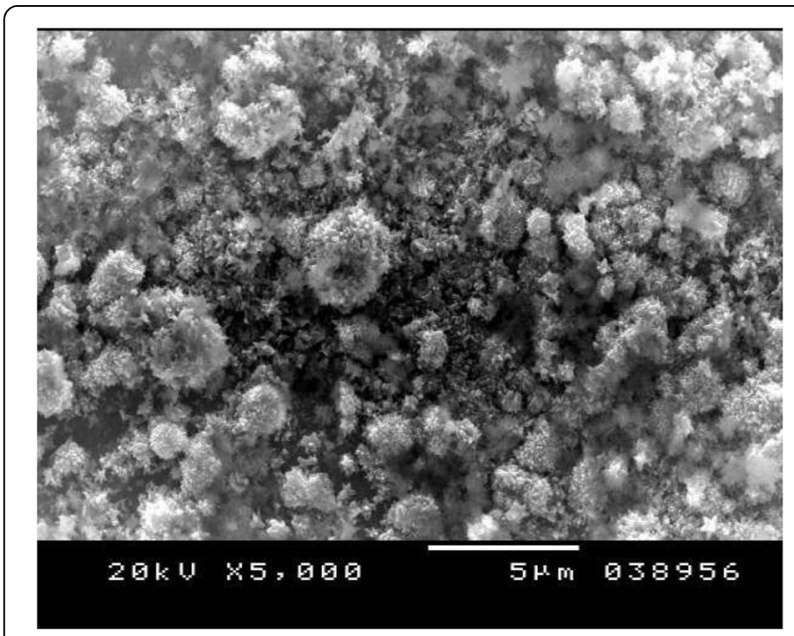

Fig. 4 Scanning electron microphotograph of $\mathrm{Cp}$ titanium specimen coated with nano HA- Zn at $\times 5000$ the same specimen. Coverage of coated substrate was computed using Matlab (version7.1) [25].

\section{Results}

\section{FT-IR results}

Figure 2 shows the FT-IR spectra of $\mathrm{Ca}\left(\mathrm{NO}_{3}\right)_{2} \cdot 4 \mathrm{H}_{2} \mathrm{O}$ with weak sharp absorption peak bands at 742, 821, and $1048 \mathrm{~cm}^{-1}$, a strong broad absorption band at $1354 \mathrm{~cm}^{-1}$, and a strong shoulder absorption band at $1455 \mathrm{~cm}^{-1}$. A wide broad absorption band peak appears at $3442 \mathrm{~cm}^{-1}$ due to the presence of water. Figure 3 shows the FT-IR spectra of HA-Zn powder scrapped from $\mathrm{CpTi}$ specimens; the band at $\sim 421 \mathrm{~cm}^{-1}$ may be

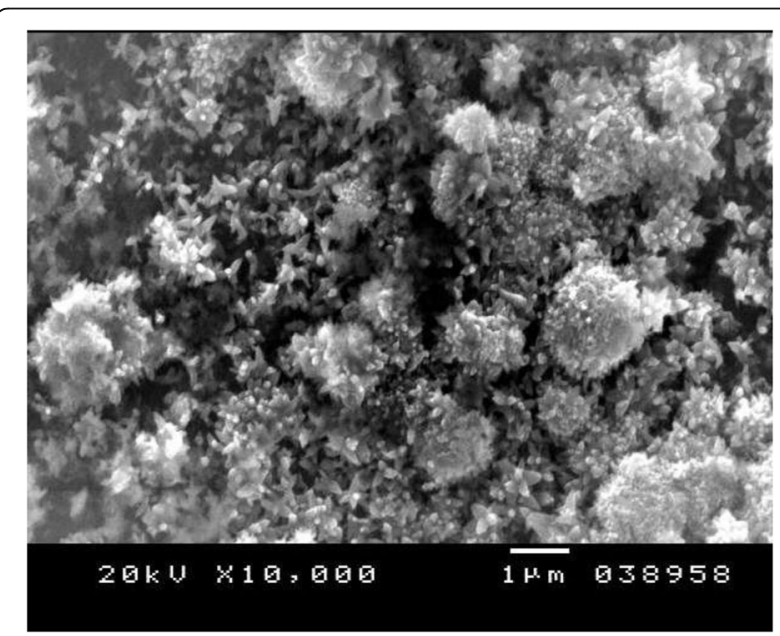

Fig. 5 Scanning electron microphotograph of Cp Titanium specimen coated with $\mathrm{HA}-\mathrm{Zn}$ at $\mathrm{X} 10,000$ 


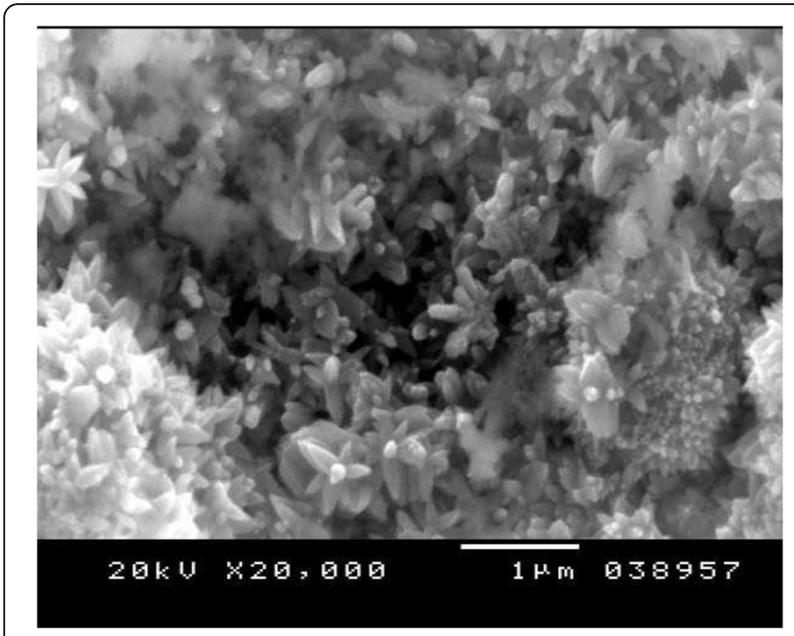

Fig. 6 Scanning electron microphotograph of $\mathrm{Cp}$ titanium specimen coated with HA-Zn at $\times 20,000$

due to the stretching vibrational mode of $\mathrm{Zn}-\mathrm{O}$. The absorption bands at $669 \mathrm{~cm}^{-1}$ and around $3448 \mathrm{~cm}^{-1}$ are due to the stretching vibration and the bending of the $\mathrm{O}-\mathrm{H}$ bond that contributes in hydrogen bond formation between water molecules adsorbed by hydroxyapatite and potassium bromide used for pellet preparation. The wide broad absorption band in the area of 1033$1269 \mathrm{~cm}^{-1}$ wave number is attributed to the stretching vibrations of $\mathrm{P}-\mathrm{O}$ bonds in the phosphate group $\left(\mathrm{PO}_{3}{ }^{-4}\right)$. The low-intensity band presented in the area of 1422$1518 \mathrm{~cm}^{-1}$ wave numbers is attributed to the stretching vibration of the $\mathrm{C}-\mathrm{O}$ bond of the carbonates $\left(\mathrm{CO}_{3}{ }^{-2}\right)$.

\section{SEM and EDS results}

Figures 4, 5, and 6 show the SE microphotographs of $\mathrm{CpTi}$ specimens coated with HA-Zn, the specimens'

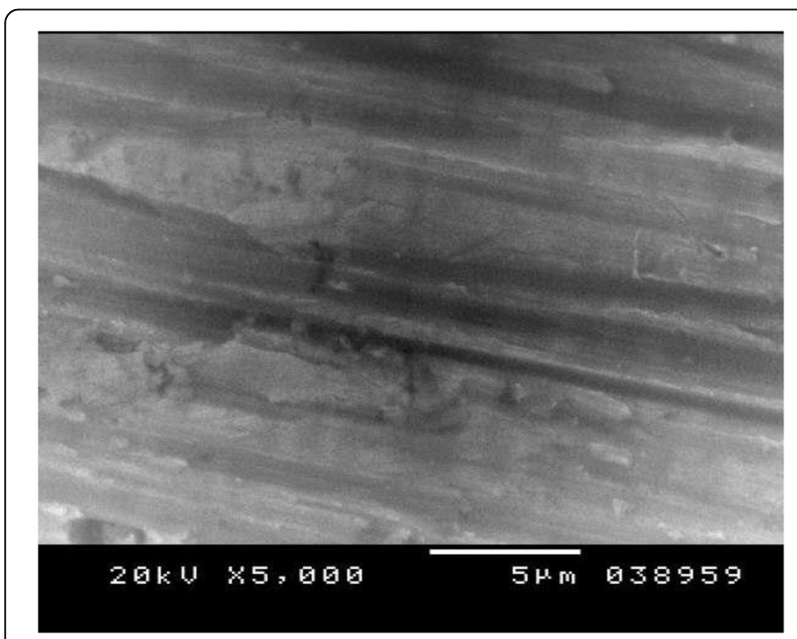

Fig. 7 Scanning electron microphotograph of control $\mathrm{Cp}$ Titanium specimen at $X 5,000$

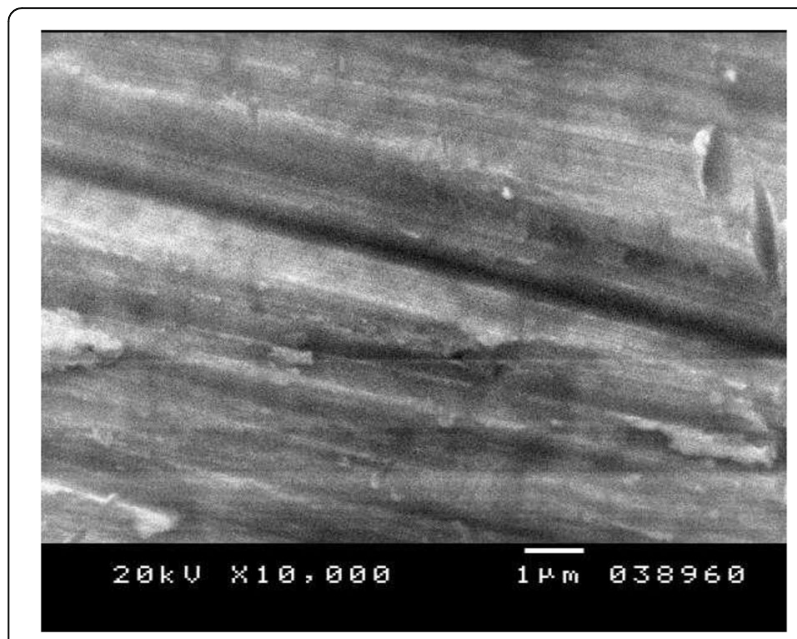

Fig. 8 Scanning electron microphotograph of control Cp titanium specimen at $\times 10,000$

surface is homogenously covered with evenly distributed globular/rosette-like nano-structures that tend to aggregate in characteristic cluster forms with little intervening porosity. On the other hand, Figs. 7, 8, and 9 show the $\mathrm{SE}$ microphotographs of control CpTi specimens with blanc surfaces; only the cutting lines of machining appear. The EDS analysis of HA-Zn shows the presence of zinc, titanium, calcium, and phosphorus; the atomic ratio of $\mathrm{Ca} / \mathrm{P}$ is 1.67 (Fig. 10). However, the control specimen only contains titanium element (Fig. 11).

\section{Roughness results}

Table 1 shows the mean average roughness value of the HA-Zn coated and control specimens; the average roughness is $0.34 \mu \mathrm{m}$ for the control group and increased significantly to be $1.09 \mu \mathrm{m}$ for the HA-Zn-

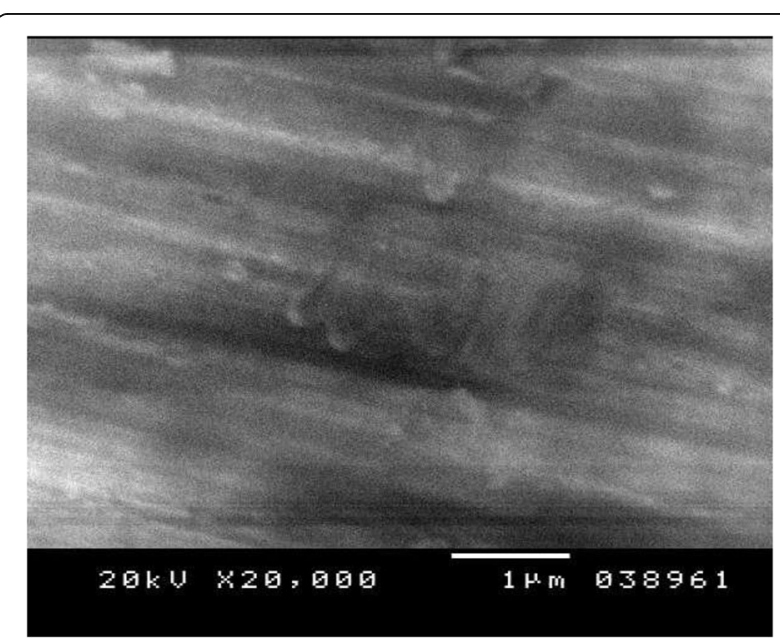

Fig. 9 Scanning electron microphotograph of control Cp titanium specimen at $\times 20,000$ 


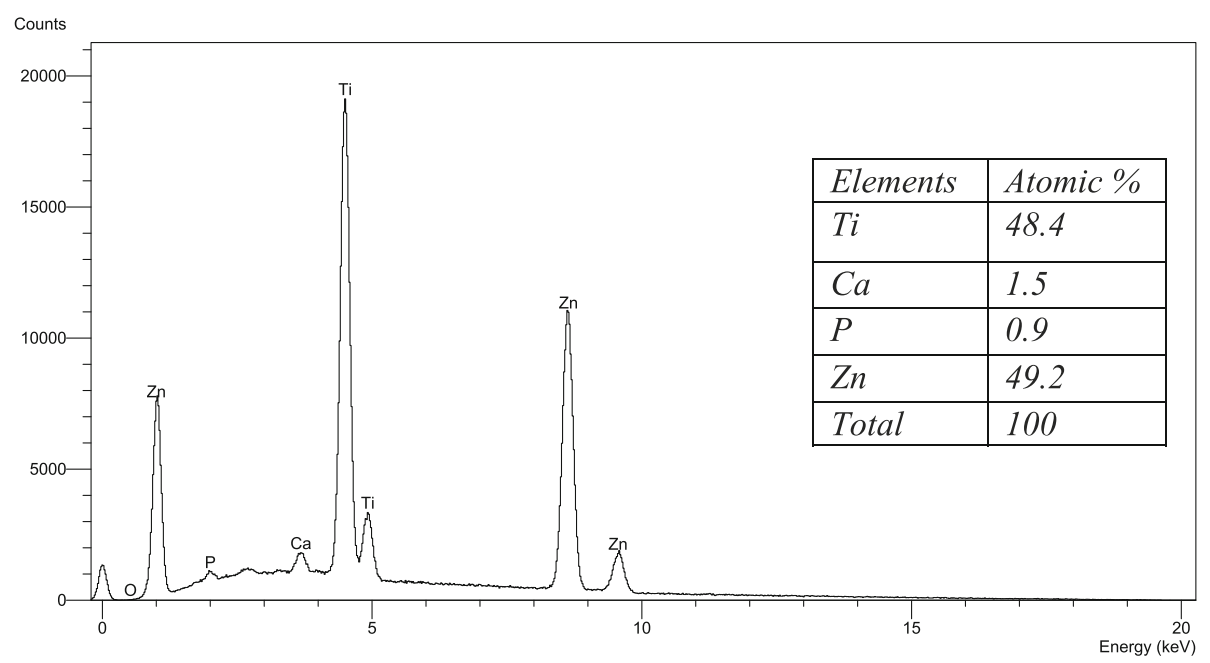

Fig. 10 Energy dispersive spectrum of $\mathrm{Cp}$ titanium specimen coated with $\mathrm{HA}-\mathrm{Zn}$

coated group $(P=0.009)$ when compared using a pair comparison of the Student $t$ test using SPSS version 20.

\section{Adhesive test results}

Following the examination of $\mathrm{X}$ cut areas after the adhesive tape removal; the adhesion was rated to be $5 \mathrm{~A}$, as no peeling or coat removal occurred along the incisions' length or at their intersection.

\section{Discussion}

Metallic orthopedic prosthesis is most commonly used due to its good mechanical properties, but its failure mostly occurs due to the lack of proper bone bonding and/or the occurrence of post-operative infections. Hydroxyapatite is commonly used as a bone filler biomaterial or as a coat for titanium prosthesis due to its decent biocompatibility, osseoconductivity, and bioactivity [26].
However, as a ceramic material, HA still has lower mechanical properties [27]. The biological apatite differs from synthetic apatite because the former contains numerous cationic substitutions, such as $\mathrm{Zn}^{2+}, \mathrm{Na}^{+}, \mathrm{Mg}^{2+}$, and has smaller size than synthetic apatite [28, 29]. It was proposed that the addition of zinc to hydroxyapatite had led to a reduction in inflammatory reaction and an improvement of bioactivity $[28,30]$.

Plasma spraying, sol-gel, and electrophoretic deposition has been all utilized to deposit HA on titanium implants, with some difficulties and worries of suppressing the HA particles' adhesion, anodic polarization of metal substrate, and increasing metals' corrosion risk [19-21]. Electrochemical deposition (ED) is the selected approach in this study due to its simplicity, easiness of parameters control, uniform coating thickness produced, and its applicability for multidimensional implant surfaces [22].

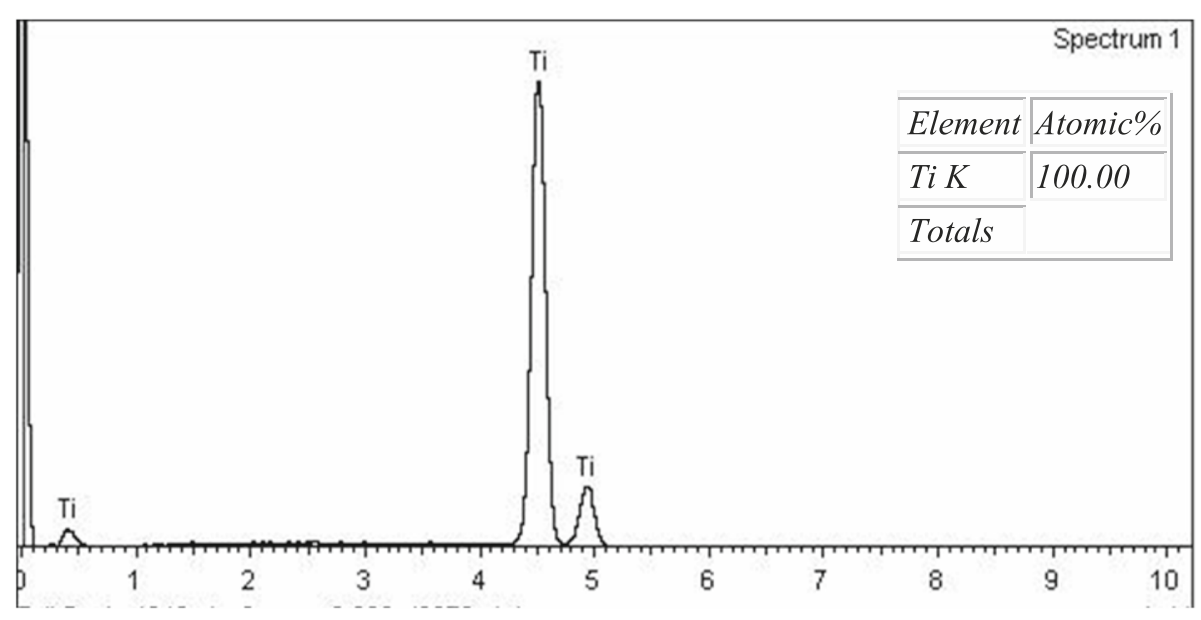

Fig. 11 Energy dispersive spectrum of control Cp titanium specimen 
Table 1 The Student $t$ test of the control and coated specimen roughness $\operatorname{Ra}(\mu \mathrm{m})$

\begin{tabular}{lllccc}
\hline & $\begin{array}{l}\text { Number of } \\
\text { specimens }\end{array}$ & Mean $\pm($ SD) & $\begin{array}{l}\text { Standard } \\
\text { error mean }\end{array}$ & $F$ value & $P$ value \\
\hline Control & 7 & $0.34 \pm(0.06)$ & 0.02 & 9.67 & $0.009^{*}$ \\
HA/Zn coated & 7 & $1.09 \pm(0.16)$ & 0.60 & & \\
\hline
\end{tabular}

In the current study, an electrochemical deposition was applied to prepare nano-HA-Zn coating on titanium metal aiming to improve bioactivity, osseointegration, and preventing peri-implantitis. At this early point of research, the coatings' procedure was accustomed to produce a uniform thickness of HA-Zn coating, characterize its chemical structure, observe its surface morphology, and evaluate the surface roughness and coat adhesive properties.

Recycling of natural-derived resources is a challenging task that may have both environmental and economical profits. Cuttlebone fishery is a naturally derived biomaterial that was used as a source of calcium during the electrochemical deposition process in this study. It was confirmed in the IR spectra (Fig. 2) that $\mathrm{Ca}\left(\mathrm{NO}_{3}\right)_{2} \cdot 4 \mathrm{H}_{2} \mathrm{O}$ resulted from the reaction of $\mathrm{CaCO}_{3}$ of cuttlebone and nitric acid [31]. The selected time for electrochemical deposition of HA-Zn coating was $2 \mathrm{~h}$; as by then, the formation of a white detectable coating had occurred and could be scrapped for IR spectral analysis. After preparation of HA-Zn coating, the analyzed powder appeared to still have the HA characterization. Li et al. prepared Zn-HA coatings through a hydrothermal method and found that the FT-IR spectra of Zn-HA has no significant changes than the as-prepared HA [32]; this $\mathrm{Zn}-\mathrm{HA}$ spectrum paralleled with this study.

Yang et al. prepared a $\mathrm{Zn}-\mathrm{HA}$ coating on Ti plates by an electrochemical process, and the SEM examination showed irregularly shaped rod-like crystals with hexagonal cross-section; this corresponded well with the current study results. They also concluded that a $\mathrm{Zn}-\mathrm{HA}$ coating improves proliferation and differentiation of osteoblasts and would enhance implant osseointegration [11].

Ceramic coatings must have good adhesion to the implant to act as a barrier and assure good protection to the substrate. The adhesion test was performed in this study to verify the adequacy of the coating thickness.

An improvement of coating adhesion occurs as their thickness decrease, although very thin coatings may not attain the protection requirements [33]. Contrariwise, it is recognized that thick ceramic coatings may develop cracks after the deposition procedure [34]. The adhesive tape test read the highest score $(5 \mathrm{~A})$; this might be attributed to the fine homogenous, closely packed, coating particles that appear crack free and highly sintered, as proved by the SEM results in Figs. 4, 5, and 6.
Dental implants do exist with various geometries, different lengths and diameters, and features, such as, pits, pores, vents, and slots. Essentially, a highly rough surface produces better initial stability and anchorage. Moreover, a rough surface with a larger surface area facilitates particles exchange between the implant and surrounding tissues. It could be concluded that such coatings with an increased surface area could have better clinical performance [35]. This developed electro-deposition process, can be applied to deposit a nano-HA-Zr coating to complex implant surfaces and thus increases their surface area, surface roughness, initial stability and clinical performance.

Supplementary, biocompatibility, anti-bacterial activity, and in vivo investigations are required to correlate between the HA- $\mathrm{Zn}$ coating properties and their effect on bone formation and osseo-integration.

\section{Conclusions}

The electro-chemical method can be employed for HA$\mathrm{Zn}$ coating deposition on titanium metal, where $\mathrm{Ca}$ source was a recycled cuttlebone fish to precipitate HA phases. Using a $\mathrm{Zn}$ anode on a low-sustained voltage was able to induce an even coat thickness of HA-Zn precipitation and increase the surface roughness significantly.

\section{Acknowledgements \\ The authors would like to express their gratitude for Dr. Sherif Kishk, Professor of Communication and Electrical Engineering, Faculty of Engineering, Mansoura University, for his help in photographing and analyzing the coating for adhesion test.}

\section{Authors' contributions}

All authors carried out the experimental study conception and design. FR helped in the experimental part of the study. NA did the data acquisition and interpretation. NE performed the statistical analysis, drafted the manuscript, and revised it critically for important intellectual content. FR had given final approval of the version to be published. All authors read and approved the final manuscript.

Competing interests

El-Wassefy N, Aref N, and Reicha F declare that they have no competing interests.

\section{Publisher's Note}

Springer Nature remains neutral with regard to jurisdictional claims in published maps and institutional affiliations.

\section{Author details}

${ }^{1}$ Dental Biomaterials Department, Faculty of Dentistry, Mansoura University, 35516 El Gomhoria St., Mansoura, Egypt. ${ }^{2}$ Physics Department, Faculty of science, Mansoura University, 35516 El Gomhoria St., Mansoura, Egypt.

Received: 20 March 2017 Accepted: 28 July 2017

Published online: 13 August 2017

\section{References}

1. Brunette DM, Tengvall $P$, Textor M TP, Textor $M$, Thomsen P. Titanium in medicine: material science, surface science, engineering, biological responses and medical applications. Springer Science \& Business Media; 2012. p.13-24. 
2. Heydenrijk K, Meijer HJA, van der Reijden WA, Vissink A, Raghoebar GM, Stegenga B. Microbiota around root-formed endosseous implants. A review of the literature. October. 2002;17:829-38.

3. El Hachmi M, Penasse M. Our midterm results of the Birmingham hip resurfacing with and without navigation. J Arthroplasty. 2014;29:808-12.

4. Abu-Amer Y, Darwech I, Clohisy JC. Aseptic loosening of total joint replacements: mechanisms underlying osteolysis and potential therapies. Arthritis Res Ther. 2007;9 Suppl 1:S6

5. Jasty M. Clinical reviews: particulate debris and failure of total hip replacements. J Appl Biomater. 1993;4:273-6.

6. Schwarz F, Sculean A, Romanos G, Herten M. Influence of different treatment approaches on the removal of early plaque biofilms and the viability of SAOS2 osteoblasts grown on titanium implants. Clin oral. 2005;9:111-7.

7. Tsang CS, Ng HMA. Antifungal susceptibility of Candida albicans biofilms on titanium discs with different surface roughness. Clin Oral Investig. 2007;11:361-8.

8. Phan T, Buckner T, Sheng J, Baldeck JD, Marquis RE. Physiologic actions of zinc related to inhibition of acid and alkali production by oral streptococci in suspensions and biofilms. Oral Microbiol. 2004;19:31-8.

9. Rossi L, Migliaccio S, Corsi A, Marzia M, Bianco P, Teti A, et al. Reduced growth and skeletal changes in zinc-deficient growing rats are due to impaired growth plate activity and inanition. J Nutr. 2001;131:1142-6.

10. Zhao S, Dong W, Jiang Q, He F, Wang X, Yang G. Effects of zinc-substituted nano-hydroxyapatite coatings on bone integration with implant surfaces. J Zhejiang Univ Sci B. 2013;14:518-25.

11. Yang F, Dong W, He F, Wang X, Zhao S, Yang G. Osteoblast response to porous titanium surfaces coated with zinc-substituted hydroxyapatite. Oral Surg Oral Med Oral Pathol Oral Radiol. 2012;113:313-8.

12. Hall SL, Dimai HP, Farley JR. Effects of zinc on human skeletal alkaline phosphatase activity in vitro. Calcif Tissue Int. 1999;64:163-72.

13. Hosea HJ, Taylor CG, Wood T, Mollard R, Weiler HA. Zinc-deficient rats have more limited bone recovery during repletion than diet-restricted rats. Exp Biol Med. 2004;299:303-11.

14. Tsai M-T, Chang Y-Y, Huang H-L, Hsu J-T, Chen Y-C, Wu AY-J. Characterization and antibacterial performance of bioactive $\mathrm{Ti}-\mathrm{Zn}-\mathrm{O}$ coatings deposited on titanium implants. Thin Solid Films. 2013;528:143-50.

15. Hu H, Zhang W, Qiao Y, Jiang X, Liu X, Ding C. Antibacterial activity and increased bone marrow stem cell functions of $\mathrm{Zn}$-incorporated $\mathrm{TiO} 2$ coatings on titanium. Acta Biomater. 2012:8:904-15.

16. Burguera-Pascu M, Rodríguez-Archilla A, Baca P. Substantivity of zinc salts used as rinsing solutions and their effect on the inhibition of Streptococcus mutans. J Trace Elem Med Biol. 2007;21:92-101.

17. Holister P, Weener JW, Vas CR, Harper T. Nanoparticles [Internet]. Vol. 3, Technology White Papers. 2003. p. 1-11. Available from: http://www. nanoparticles.org/pdf/Cientifica-WP3.pdf

18. Surmenev RA, Surmeneva MA, Ivanova AA. Significance of calcium phosphate coatings for the enhancement of new bone osteogenesis-a review. Acta Biomater. 2014;10(2):557-79.

19. Kar A, Raja KS, Misra M. Electrodeposition of hydroxyapatite onto nanotubular TiO2 for implant applications. Surf Coatings Technol. 2006;201:3723-31.

20. Manso M, Jiménez C, Morant C, Herrero P, Martínez-Duart J. Electrodeposition of hydroxyapatite coatings in basic conditions. Biomaterials. 2000;21:1755-61.

21. Prasad BE, Kamath PV. Electrodeposition of dicalcium phosphate dihydrate coatings on stainless steel substrates. Bull Mater Sci. 2013;36:475-81.

22. Lu X, Zhao Z, Leng Y. Calcium phosphate crystal growth under controlled atmosphere in electrochemical deposition. J Cryst Growth. 2005:284:506-16.

23. Battistella E, Mele S, Pietronave S, Foltran I, Lesci Gl, Foresti E, et al. Transformed cuttlefish bone scaffolds for bone tissue engineering. Adv Mater Res. 2010;89-91:47-52.

24. Specification of ISO E. 4287-Geometrical Product Specifications (GPS) Surface Texture: Profile Method-Terms, Definitions and Surface Texture Parameters. International Organization for Standardization, Genève. 1997.

25. ASTM Committee D-1 on Paint and Related Coatings, Materials, and Applications. Standard test methods for measuring adhesion by tape test. ASTM International; 2009

26. Kuo MC, Yen SK. The process of electrochemical deposited hydroxyapatite coatings on biomedical titanium at room temperature. Mater Sci Eng C. 2002;20:153-60
27. Suchanek W, Yoshimura M. Processing and properties of hydroxyapatitebased biomaterials for use as hard tissue replacement implants. J Mater Res. 1998;13:94-117.

28. Kohli S, Batra U, Kapoor S. Influence of zinc substitution on physicochemical and in vitro behaviour of nanodimensional hydroxyapatite. Asian J Eng App Technol. 2014;3:63-7.

29. Ginebra MP, Driessens FCM, Planell JA. Effect of the particle size on the micro and nanostructural features of a calcium phosphate cement: a kinetic analysis. Biomaterials. 2004;25:3453-62.

30. Grandjean-Laquerriere A, Laquerriere P, Jallot E, Nedelec JM, Guenounou M, Laurent-Maquin D, et al. Influence of the zinc concentration of sol-gel derived zinc substituted hydroxyapatite on cytokine production by human monocytes in vitro. Biomaterials. 2006:27:3195-200.

31. Norwitz G, Chasan DE. Application of infrared spectroscopy to the analysis of inorganic nitrates phase I: spectra of inorganic nitrates in acetome and the use of such spectra in analytical chemistry. Philadelphia, Pa; No. FA-T687-1 Quality Assurance. 1968. Directorate.

32. Li M, Xiao X, Liu R, Chen C, Huang L. Structural characterization of zincsubstituted hydroxyapatite prepared by hydrothermal method. J Mater Sci Mater Med. 2008:1;19:797-803.

33. Fernandez-Pradas JM, Clèries L, MartmHnez E, Sardin G, Esteve J, Morenza JL. Influence of thickness on the properties of hydroxyapatite coatings deposited by KrF laser ablation. Biomaterials. 2001;22:2171-5.

34. Ribeiro AAA, Balestra RMM, Rocha MNN, Peripolli SBB, Andrade MCC, Pereira LCC, et al. Dense and porous titanium substrates with a biomimetic calcium phosphate coating. Appl Surf Sci. 2013:265:250-6.

35. Lee B-H, Lee C, Kim D-G, Choi K, Lee KH, Do Kim Y. Effect of surface structure on biomechanical properties and osseointegration. Mater Sci Eng C. 2008;28:1448-61.

\section{Submit your manuscript to a SpringerOpen ${ }^{\circ}$ journal and benefit from:}

- Convenient online submission

- Rigorous peer review

- Open access: articles freely available online

- High visibility within the field

Retaining the copyright to your article

Submit your next manuscript at $>$ springeropen.com 